\title{
Review Article \\ Thyroid Antibodies and Miscarriage: Where Are We at a Generation Later?
}

\begin{abstract}
Alex Stagnaro-Green
George Washington University School of Medicine and Health Sciences, 2300 Eye Street, Ross Hall, Suite 712, Washington, DC 20037, USA

Correspondence should be addressed to Alex Stagnaro-Green, msdasg@gwumc.edu

Received 4 February 2011; Accepted 10 March 2011

Academic Editor: Bijay Vaidya

Copyright ( 2011 Alex Stagnaro-Green. This is an open access article distributed under the Creative Commons Attribution License, which permits unrestricted use, distribution, and reproduction in any medium, provided the original work is properly cited.

In 1990, an association between thyroid antibody positivity and spontaneous miscarriage was first reported. A generation has passed since the initial observation. Over that time a robust literature has developed which has confirmed the initial finding and expanded upon it. The present paper reviews the literature that has been generated over the last twenty years on the following topics: (1) thyroid antibodies and spontaneous miscarriage, (2) thyroid antibodies and recurrent abortion, (3) etiology of pregnancy loss in thyroid antibody positive women, and (4) discussion of future research directions.
\end{abstract}

\section{Introduction}

It has been twenty years since the first paper reporting an association between thyroid antibodies and spontaneous miscarriage in euthyroid women was published [1]. The finding was serendipitous as the study was designed to evaluate the prevalence and etiology of postpartum thyroiditis. Five hundred and fifty-two women in the New York metropolitan area were screened in the first trimester of pregnancy for thyroid function and thyroid antibody status. A cohort of antibody positive and antibody negative women were selected and followed prospectively throughout pregnancy and into the postpartum period. As the study progressed, a high incidence of spontaneous miscarriage was observed in the cohort. In particular, it appeared that the miscarriage rate was disproportionately higher in women who were thyroid antibody positive. Following much discussion within the research team, as there was no known association between thyroid autoimmunity and miscarriage, nor was there a plausible mechanism, it was decided to examine the pregnancy outcome in the 552 women who were initially screened. A doubling of the miscarriage rate was found $(17 \%$ versus $8.4 \%, P=.011)$ and reported in the Journal of the American Medical Association. It was unclear at the time if the finding was a statistical fluke or in fact represented an important association.

A generation has passed since the initial observation. Over that time a robust literature has developed which has not only confirmed the initial observation but expanded upon it. The present paper will summarize the data that has been published over the ensuing 20 years and speculate upon future directions. In particular, the areas of focus will be (1) thyroid antibodies and spontaneous miscarriage, (2) thyroid antibodies and recurrent abortion, (3) etiology of pregnancy loss, and (4) future directions. A comprehensive metaanalysis was published last year on the relationship between thyroid antibodies and in vitro fertilization (IVF) demonstrating that thyroid autoimmunity in women undergoing IVF is associated with an increased rate of pregnancy loss [2]. Consequently, the present discussion will not include a review of the IVF and thyroid antibody literature on spontaneous miscarriage.

\section{Thyroid Antibodies and Pregnancy Loss}

As noted above, Stagnaro-Green et al. reported a statistically significant doubling in the miscarriage rate in American euthyroid women in the first trimester of pregnancy who 
were thyroid antibody positive. Of the 552 women initially screened, 57 were unavailable for followup. One hundred women were thyroid antibody positive (with a miscarriage rate of $17 / 100$ or $17 \%$ ), and 392 women were antibody negative (with a miscarriage rate of $33 / 392$ or $8.4 \%$ ). Prior to the 1990 paper the only antibody shown to be associated with spontaneous miscarriage was anticardiolipin antibody. Analysis of the sera of the 50 women who miscarried revealed no difference in percentage of women who were cardiolipin antibody positive between women who were thyroid antibody positive and miscarried versus women who were thyroid antibody negative and miscarried. There were also no demographic differences between the groups. The TSH level was slightly, but not significantly, higher in the thyroid antibody positive women as compared to thyroid antibody negative controls (TSH-2.35 mIU/L versus $1.60 \mathrm{mIU} / \mathrm{L}$, resp., $P=.12$ ). Finally, no difference in thyroid antibody titers were noted in antibody positive women who miscarried as compared to antibody women who carried to term.

Glinoer and colleagues in 1991 [3] reported findings of a prospective study of 120 Belgian euthyroid women with mild thyroid abnormalities (nodules, goiter or thyroid antibody positivity) and 630 euthyroid controls. The goal of the study was to evaluate the progression of thyroid function tests throughout pregnancy and assess for adverse obstetrical and/or neonatal outcomes. Women with thyroid autoimmunity ( $n=45$ ) were found to have a dramatic increase in spontaneous miscarriage when contrasted to controls $(13.3 \%$ versus $3.3 \%, P<.001)$. As found in the study by Stagnaro-Green et al. there was no association with anticardiolipin antibody or thyroid antibody titer. Further analysis of the study was published by Lejeune et al. in 1993 [4]. Specifically, analysis of first trimester pregnancy loss revealed a spontaneous miscarriage rate of $24 \%$ in thyroid antibody positive women when compared to $5 \%$ in controls $(P<.005)$.

In 1997, Iijima and colleagues evaluated 1179 healthy pregnant Japanese women between 6-14 weeks gestation for the presence of seven autoantibodies [5]. A doubling of the miscarriage rate was reported in antithyroid microsomal antibody positive women as contrasted to women who were negative for all seven autoantibodies (10.4\% versus 5.5\%, resp., $P<.05)$. Furthermore, the rate of small for gestational age births (SGA) was increased in microsomal antibody women when compared to controls (7.1\% versus $3.4 \%)$. The thyroid antibody titer was related to neither the rate of spontaneous miscarriage nor the rate of SGA.

Bagis and colleagues published a study of 876 Turkish women initially screened at 12 weeks gestation [6]. All women had thyroid function tests and thyroid autoantibodies performed at 12 weeks gestation, revealing an antibody positive rate in the entire cohort of $12.3 \%(P<.0001)$. Fifty percent of the antibody-positive group had a history of a prior miscarriage as contrasted to only $14.1 \%$ in the antibody negative group $(P<.0001)$. TSH levels were significantly higher in antibody-positive women with a history of miscarriage as compared to antibody women who had carried to term $(1.90 \mu \mathrm{U} / \mathrm{mL}$ versus $1.2 \mu \mathrm{U} / \mathrm{mL}$,
$P<.006)$. Free T4 values were also lower in the antibody positive women with a history of miscarriage $(11.0 \mathrm{pmol} / \mathrm{L}$ versus $12.7 \mathrm{pmol} / \mathrm{L}, P<.05)$.

In 2006, Ghafoor et al. evaluated 1500 Pakistani women for thyroid peroxidase antibodies and thyroid function tests during pregnancy. Women were followed throughout gestation to determine pregnancy outcome [7]. Thyroid antibody positive women, which comprised $11.2 \%$ of the cohort, had a spontaneous miscarriage rate of $36.3 \%$ as compared to $1.8 \%$ in antibody negative women $(P<.01)$. A significantly higher rate of prematurity was also reported $(26.8 \%$ versus $8.0, P<.01)$ in antibody positive women. All 1500 women in the study were euthyroid.

In 2006, Negro et al. reported the findings of a prospective intervention trial. Nine hundred and eighty-four women from southern Italy in the first trimester of pregnancy were evaluated for thyroid function and thyroid peroxidase [8]. Women who were antibody positive $(n=115)$ were divided into two groups. Half of the antibody positive women were given levothyroxine during pregnancy $(n=$ 57 ), the dose of which was determined by their initial TSH level and thyroid antibody titer. The remaining antibody positive women $(n=58)$, along with 869 antibody negative controls, did not receive levothyroxine intervention. The rate of spontaneous miscarriage was $13.8 \%$ in untreated thyroid antibody positive women and $2.4 \%$ in the 890 controls $(P<.05)$. Thyroid antibody positive women who received levothyroxine had a spontaneous miscarriage rate of $3.5 \%$ which was similar to controls $(2.4 \%)$, and statistically lower then the miscarriage rate in the untreated thyroid antibody positive group $(13.8 \%)(P<.05)$. Thyroid antibody positive women who were not treated with levothyroxine had higher TSH levels at 20 weeks, 30 weeks, and three days postdelivery when compared to controls or thyroid antibody-positive women who were given levothyroxine. The largest difference was seen postdelivery (TSH-1.9 mIU/L in levothyroxine treated antibody positive women, TSH$3.5 \mathrm{mIU} / \mathrm{L}$ in untreated antibody positive women, TSH$2.1 \mathrm{mIU} / \mathrm{L}$ in controls, $P<.01)$. Free T4 values were also lower in the untreated group at 30 weeks and postdelivery when compared to treated antibody positive women or controls (postdelivery values were $10.2 \mathrm{ng} / \mathrm{liter}, 14.3 \mathrm{ng} / \mathrm{liter}$, and $14.6 \mathrm{ng}$ /liter, resp., $P<.01$ )

In summary, a total of seven studies (see Table 1) in six different countries have reported an association between thyroid antibody positivity in unselected women in the first trimester of pregnancy and spontaneous miscarriage (see Figure 1). It can therefore be concluded that there is a clear and consistent association between thyroid antibody positivity and pregnancy loss. Studies have excluded cardiolipin antibody as a potential explanation for the pregnancy loss.

\section{Recurrent Abortion}

Shortly after the initial publication demonstrating an association between thyroid antibody positivity and spontaneous miscarriage, researchers began evaluating women with recurrent abortion. Recurrent abortion occurs in $0.5-1 \%$ 


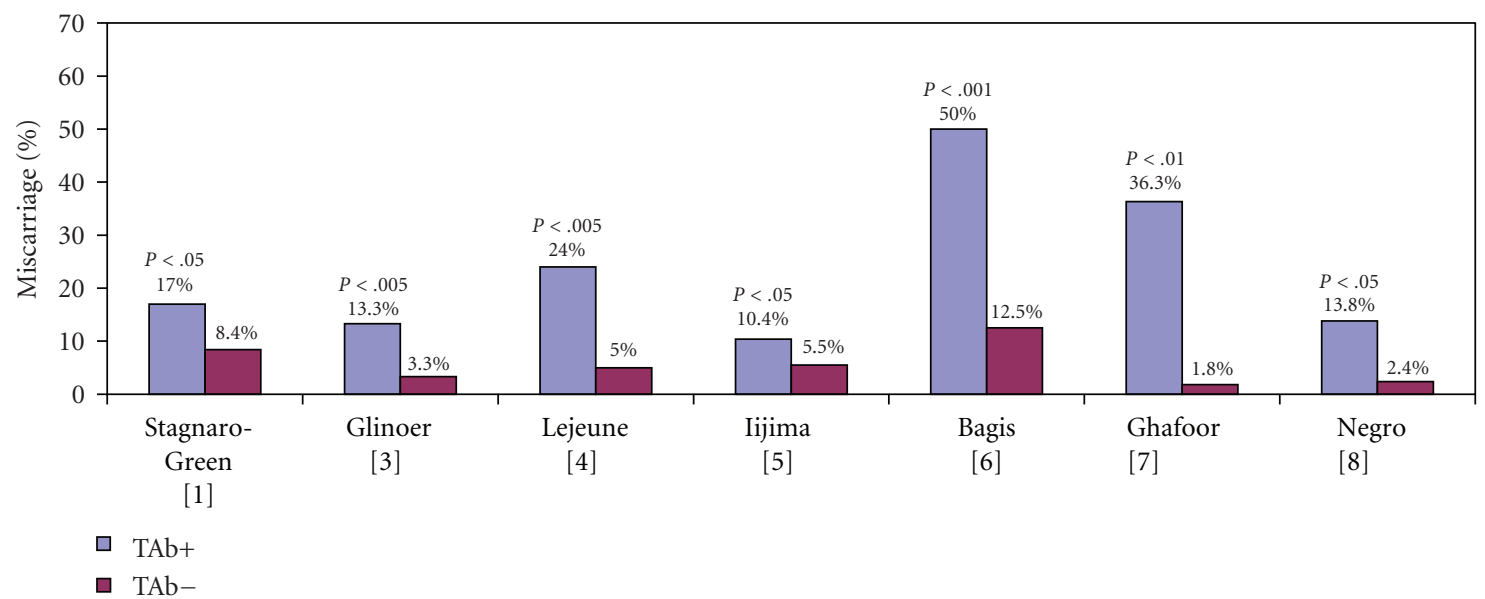

FIGURE 1: Percentage of spontaneous miscarriage in unselected pregnancies in women who were thyroid antibody positive (TAb+) and thyroid antibody negative (TAB-).

TABLE 1: Country of origin and number of women in each study of Figure 1.

\begin{tabular}{lccc}
\hline Author & Country & TAb + & TAb- \\
\hline Stagnaro-Green et al. [1] & USA & 100 & 392 \\
Glinoer et al. [3] & Belgium & 45 & 360 \\
Lejeune et al. [4] & Belgium & 23 & 340 \\
Iijima et al. [5] & Japan & 24 & 52 \\
Bagis et al. [6] & Turkey & 108 & 768 \\
Ghafoor et al. [7] & Pakistan & 212 & 1288 \\
Negro et al. [8] & Italy & 115 & 869 \\
\hline
\end{tabular}

of all women and is defined as three or more spontaneous miscarriages. The etiology is multifactorial, and includes uterine anomalies, endocrine disorders, genetic defects, and the anticardiolipin antibody. Nevertheless, despite comprehensive workups, approximately $50 \%$ of women with recurrent abortion will have no identified etiology. It is therefore not surprising that multiple research groups have studied the relationship between thyroid antibody positivity in women with recurrent abortion.

The first two studies investigating women with recurrent abortion were published in 1993 and performed by Pratt and colleagues in Chicago. The first study examined 45 women with recurrent abortion for four polynucleotides, five histones, six phospholipids, and thyroid antibodies [20]. Thirty-one percent of the recurrent aborters were thyroid antibody positive as compared to $19 \%$ in a control group of 100 normal blood donors $(P=\mathrm{ns})$. The study was limited by the composition of the controls which included 46 men, and the small size of the group of women with recurrent abortion. Pratt and colleagues then performed a prospective study evaluating the outcome of a subsequent pregnancy in 42 women with recurrent abortion [9]. Thirty-one percent of the 42 women were thyroid antibody positive $(n=13)$ with 12 of the 42 women experienced a recurrent abortion in the subsequent pregnancy. Of the twelve women who miscarried, eight were thyroid antibody positive $(8 / 12=67 \%)$. In comparison, only five of the thirty who went to term were thyroid antibody positive $(17 \%)(P=.003)$. The authors concluded that in women with recurrent abortion the presence of thyroid antibody positivity was associated with an increased rate of pregnancy loss in a subsequent pregnancy.

Bussen and Steck also published two papers on the topic of thyroid antibodies and recurrent abortion. The first study was published in 1995 and evaluated 66 German women for thyroid antibody positivity. Three groups were studied, including 22 euthyroid nonpregnant women with recurrent abortion, 22 multigravida women without endocrine disorders, and 22 nulligravida women [10]. The recurrent abortion group had a significantly higher rate of antibody positivity $(36 \%)$ then either the euthyroid nonpregnant controls (5\%) (36\% versus $5 \%, P<.01)$, or the nulligravida controls (9\%) $(36 \%$ versus 9\%, $P<.01)$. In their 1997 paper, Bussen and Steck evaluated 28 euthyroid nonpregnant women with recurrent abortion for thyroid antibodies and nonorgan specific antibodies [12]. Secondary causes of recurrent abortion were excluded in all 28 women. Thirty-nine percent ( $n=11 / 28$ ) of the women with recurrent abortion were positive for thyroid antibodies versus $7 \%(n=2 / 28)$ of multigravida controls $(P<.01)$. No correlation was found between the presence of phospholipid antibodies and thyroid antibody positivity.

In a small study performed by Roberts et al. in Scotland in 1996, thyroid antibody positivity rate was evaluated in 11 women with recurrent abortion, 11 healthy pregnant women, 10 nonpregnant women, 11 women with a spontaneous miscarriage, and 10 women who had an elective termination of pregnancy [11]. Thirty-six percent (4/11) of the women with a history of recurrent abortion were thyroid antibody positive as opposed to five percent (2/41) of the women in the other four groups $(P<.01)$. Roussev et al. also performed a small study consisting of 45 women with recurrent abortion and 15 healthy controls [21]. No difference was found in the thyroid antibody positivity rate between the two groups ( $9 \%$ versus $0 \%, P=n s)$. 
Interpretation of the results of both studies are limited by their small sample size.

In 1998, Esplin et al. published a study performed in Salt Lake City, Utah comparing the incidence of thyroid antibody positivity in 74 nompregnant women with recurrent abortion with 75 healthy nonpregnant controls of similar gravidity [13]. Women included in the recurrent abortion group had all tested negative for secondary causes of pregnancy loss. Although the thyroid antibody positivity rate in the recurrent abortion group was elevated at $29 \%$ the control group had an unusually high rate of thyroid antibody positivity of $37 \%$ $(P=\mathrm{ns})$. It is unclear if geographic differences in rates of thyroid antibody positivity was a confound in this study.

In the largest study performed to date, Kutteh and colleagues in 1999 compared the rate of thyroid antibody positivity in 700 women with a minimum of two spontaneous miscarriages and in whom secondary causes of pregnancy loss were excluded, to 200 healthy controls [14]. All sera were obtained at least three months following a spontaneous miscarriage or birth. Thyroid antibody positive rate was significantly higher in the recurrent abortion group when compared to the controls $(22.5 \%$ versus $14.5 \%, P=$ $.01)$. There was no difference between the groups in regards to percentage of women with abnormally elevated TSH values; however women with a history of recurrent abortion were older then controls (33.3 years versus 30.8 years, $P<$ $.01)$.

Four more studies with either limited numbers of participants, or lack of a control group, were published in 1999 and 2000. Rushworth et al. evaluated the pregnancy outcome of 24 antibody-positive euthyroid British women with a history of recurrent abortion through a subsequent pregnancy. Eighty-one thyroid antibody negative women with recurrent abortion served as controls [22]. The live birth rate of the two groups was identical at 58\%. Although the authors concluded that thyroid antibody positivity in women with recurrent abortion does not portend a worse outcome when compared to women who are thyroid antibody negative, interpretation of the results are limited by the small number of thyroid antibody positive women evaluated $(n=24)$. ReznikoffEtievant et al. evaluated 678 French women with recurrent abortion and found a prevalence rate of thyroid antibody positivity of $2.9 \%$. The study did not include a control group and did not address the unusually low rate of thyroid anitbody positivity [23]. Dendrinos et al. reported a thyroid antibody positivity rate of $37 \%$ in 30 Greek women with recurrent abortion as compared to $13 \%$ of 15 age-matched controls $(P<.05)$ [15]. Finally, Mecacci reported that $37.9 \%$ $(11 / 29)$ of women with recurrent abortion were antithyroid antibody positive as compared to $14.5 \%$ (10/69) of controls $(P<.02)[16]$.

In 2002, Abdel Aziz et al. [24] performed a prospective study that was similar in design to the second investigation performed by Pratt et al. in 1993 [9]. Fifty Egyptian women with a history of recurrent abortion were tested for thyroid antibodies and followed until the 20th week of pregnancy. Eighteen $(36 \%)$ of the women had the presence of thyroid antibodies. Twelve of the eighteen women (67\%) went on to have another spontaneous miscarriage as compared to $15.6 \%$
$(5 / 32)$ of the thyroid antibody negative women $(P<.001)$. These results are almost identical to the findings reported by Pratt and colleagues [9]. Antibody-positive women were older (33.1 years versus 29.0 years, $P<.01$ ), had a larger thyroid volume $(23.9 \mathrm{~mL}$ versus $19.3 \mathrm{~mL}, P<.001)$ and reported a higher number of prior abortions (5.1 versus 3.9, $P<.05)$ as compared to antibody-negative women.

A large scale study prospective trial comparing successful pregnancy in three groups of women with recurrent abortion was performed by De Carolis et al. in 2004 [25]. Group 1 consisted of women who were thyroid antibody positive but antiphospholipid syndrome (APS) negative $(n=162)$, group 2 women were APS positive but antithyroid antibody negative $(n=149)$, and group 3 women were both APS and thyroid antibody positive $(n=54)$. The group with the highest percentage of successful pregnancy outcome was Group 2 $(92 \%)$, whereas the two groups of women who were thyroid antibody positive had significantly lower rates of successful pregnancies (Group 1-57\%, Group 3-60\%, $P=.0003$ ).

Another study published in 2004 was conducted by Marai et al. who evaluated 58 Israeli women [17]. Thirty-eight of the women had a history of recurrent abortion and 20 women had a history of infertility but no pregnancy losses. Thyroid antibody positivity rate was significantly higher in the women with recurrent abortion (21\%) when compared to the thyroid antibody positive rate in women with a history of infertility $(0 \%)(P=.001)$.

Shoenfeld and colleagues evaluated 109 women with recurrent pregnancy loss and compared the rate of thyroid antibody positivity to 120 healthy controls. Results on the presence of thyroid peroxidase or antithyroglobulin antibodies were only presented for 24 of the women with recurrent abortion. Thirty-three percent of the 24 women $(8 / 24)$ were positive for thyroid antibodies as compared to only $11.2 \%(14 / 120)$ of the healthy controls (OR-3.79 $\{\mathrm{CI}-$ $1.2-11.7\})[18]$.

The most recent papers on thyroid antibodies and recurrent abortion were published in 2008. The first was a case control study performed by Iravani et al. [19] in Iran which included 641 women with three or more consecutive pregnancy losses and 269 age-matched controls. Women in the recurrent abortion group had a rate of thyroid antibody positivity almost twice that of the control group (24.5\% versus $12.6 \%, P<.001)$. Mean TSH levels were higher in the recurrent abortion group when compared to controls (TSH-1.93 mIU/L versus $1.3 \mathrm{mIU} / \mathrm{L}, P<.001$ ) and was independently associated with both pregnancy loss and autoimmunity. In a much smaller study, Bellver et al. found no difference in thyroid antibody positivity between 30 Spanish women with recurrent abortion and 32 controls (3.6\% versus $15.6 \%$ ) [26].

In conclusion, there have been 17 studies performed to date comparing thyroid antibody positivity rate in women with recurrent abortion as compared to control groups. The studies vary markedly in regards to the size of the population studied and have taken place in five different countries. Thirteen of the seventeen studies performed demonstrated a significant increase in the thyroid antibody positivity rate in women with recurrent abortion (Table 2, Figure 2). Of 


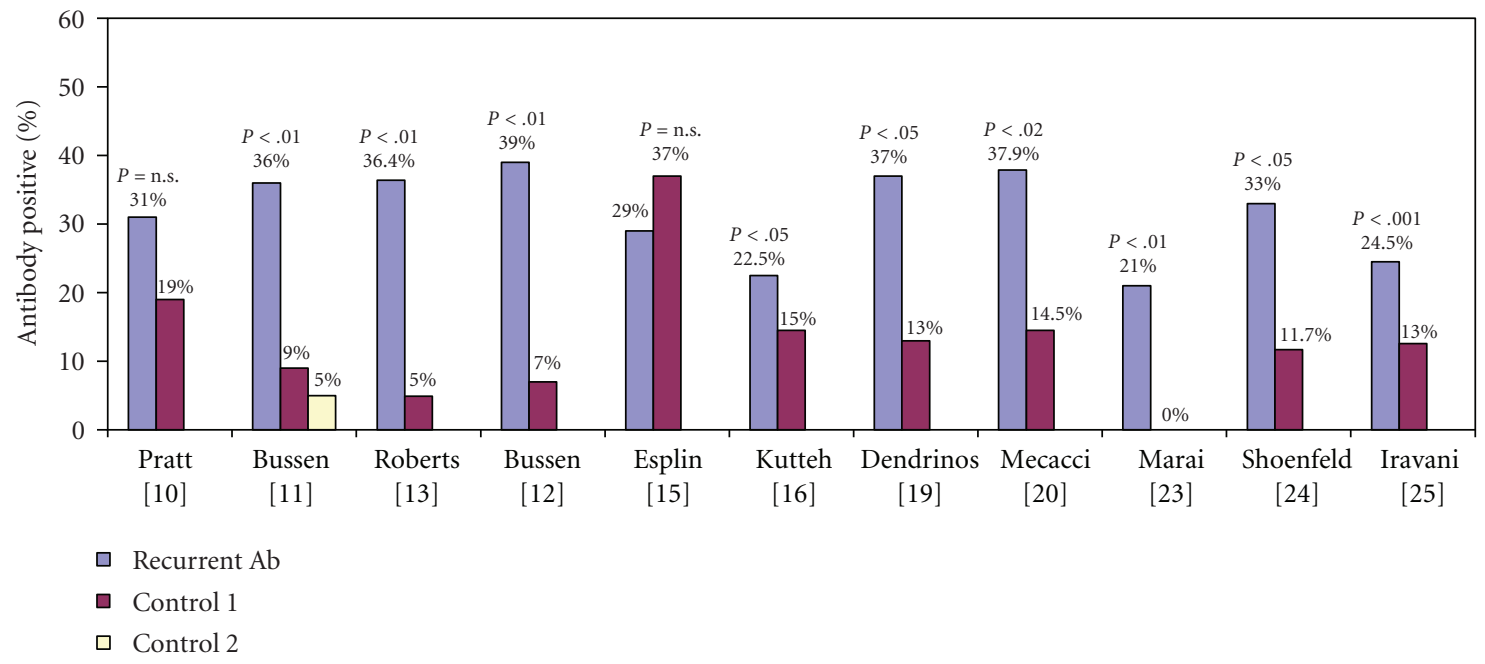

FIgURE 2: Percentage of thyroid antibody positivity in women with recurrent abortion (Recurrent $\mathrm{Ab}$ ) and controls.

interest, the three negative studies were all performed in the United States.

\section{Etiology of Pregnancy Loss}

The etiology of pregnancy loss in thyroid antibody-positive women remains to be elucidated. Two meta-analyses have reported a difference in the mean age and mean TSH level between thyroid antibody-positive and thyroid antibodynegative women who miscarry $[27,28]$. In the most recent meta-analysis, the mean TSH difference between groups was $0.61 \mathrm{mIU} / \mathrm{L}(1.7 \mathrm{mIU} / \mathrm{L}$ versus $1.1 \mathrm{mIU} / \mathrm{L}, P<.00001)$ [28]. Although the TSH levels are well within the normal range, a 2009 study by Benhadi et al. reported a statistically significant increase in child loss (defined as miscarriage, fetal, or neonatal death) with increasing levels of TSH between $0.34-5.60 \mathrm{mIU} / \mathrm{L}$ [29]. Similarly, Negro et al. found a $69 \%$ increase in the rate of miscarriage in thyroid antibody negative women with TSH values between $2.5-5.0 \mathrm{mIU} / \mathrm{L}$ as compared to thyroid antibody negative women with TSH values below $2.5 \mathrm{mIU} / \mathrm{L}(6.1 \%$ versus $3.6 \%, P=.006)$ [30]. Consequently, it is feasible that a component of the increased risk of pregnancy loss in thyroid antibody positive women could be attributable to increased TSH levels. On the other hand, the age difference reported in the metaanalysis of 1.3 years $(P<.003)[28]$ appears to be limited to explain the marked difference in pregnancy loss between thyroid antibody positive and negative women. In support of this contention, Nybo Anderson et al. evaluated pregnancy outcome in 634,272 women and found only a minimal increase in the miscarriage rate between maternal ages 20 to 30 and approximately a $1.5 \%-2.0 \%$ increase in the miscarriage rate for each year between the maternal age of 30 to 40 [31].

Three research groups have evaluated the role of thyroid antibodies in pregnancy loss in an animal model. In 2001,
TABLE 2: Country of origin and number of women in each study of Figure 2.

\begin{tabular}{lccc}
\hline Author & Country & TAb + & TAb- \\
\hline Pratt et al. [9] & USA & 45 & 100 \\
Bussen et al. [10] & Germany & 22 & 22 \\
Roberts et al. [11] & Scotland & 11 & 41 \\
Bussen et al. [12] & Germany & 28 & 28 \\
Esplin et al. [13] & USA & 74 & 75 \\
Kutteh et al. [14] & USA & 700 & 200 \\
Dendrinos et al. [15] & Greece & 30 & 15 \\
Mecacci et al. [16] & Italy & 29 & 69 \\
Marai et al. [17] & Israel & 38 & 20 \\
Shoenfeld et al. [18] & Italy & 33 & 120 \\
Iravani et al. [19] & Iran & 64 & 269 \\
\hline
\end{tabular}

Imaizumi and colleagues evaluated the effect of experimental autoimmune thyroiditis on pregnancy outcome in a murine model of thyroglobulin immunized female mice [32]. Autoimmune thyroiditis and pregnancy loss were enhanced, but only when specific strains of mice were mated. Class II MHC antigens were found on placental cells from thyroglobulin induced mice but not on controls. The authors concluded that the pregnancy loss detected in the murine model of autoimmune thyroiditis was related to paternal antigens.

Matalon et al. in 2003 immunized and mated BALB/c mice with either human thyroglobulin or complete Freund's adjuvant (the control group) [33]. No difference in thyroid function tests were found between the two groups of mice. Animals immunized with human thyroglobulin developed high titers of antithyroglobulin antibodies and antibodies to thyroglobulin on the placenta. The rate of resorbed fetuses was higher in the immunized animals. Immunized animals also had lower placental and fetal weights. Interestingly, Mannisto et al. reported higher placental weights in thyroid 
peroxidase antibody mothers, but not in thyroglobulin antibody women [34]. In 2009, Lee et al. reported similar findings to Matalon et al. in a study that immunized female C57bl/6 mice with recombinant mouse thyroid peroxidase [35]. Compared to controls, immunized mice had a significantly higher rate of resorped fetuses and a reduced liter size. The authors concluded that antithyroid peroxidase antibody may impact embryo development postimplantation.

To date, the only prospective randomized controlled treatment in thyroid antibody-positive euthyroid women was performed by Negro et al. in 2006 [8]. The rate of miscarriage was compared between 57 thyroid peroxidase antibody women who were given levothyroxine beginning in the first trimester of pregnancy with 58 euthyroid thyroid antibody positive women who were not given levothyroxine (the control group). As noted earlier, the dose of levothyroxine administered was based on a combination of initial TSH level and titer of thyroid antibody. A statistically significant decrease in spontaneous miscarriage was seen in the group of treated women as compared to the controls (3.5\% versus $13.8 \%, P<.05)$.

\section{Future Directions}

Summarizing the studies which have been published over the last generation, the following can be concluded: (1) thyroid antibody positivity is associated with pregnancy loss in unselected pregnancies, (2) thyroid antibody positivity is associated with pregnancy loss in women with recurrent miscarriage, (3) murine data have demonstrated a direct impact of immunization of female mice, with either thyroglobulin or thyroid peroxidase, and the development of thyroid antibodies along with decreased litter size, fetal resorption, and diminished placental weight, and (4) the results of the study by Negro et al. demonstrating a decreased rate of pregnancy loss in euthyroid thyroid antibody-positive women are exciting initial data but need to be replicated. Future directions should include the following: (1) an expansion of the murine model in order to further elucidate potential pathophysiological etiologies, (2) studies of immune markers in thyroid antibody-positive pregnant women, (3) studies of placentas of thyroid antibody positive pregnant women who miscarry, (4) studies further separating the impact of thyroid antibodies and TSH differences (within the reported normal range for pregnancy) on miscarriage, and (5) replication of the study by Negro et al. Many answers should be forthcoming in the generation ahead.

\section{References}

[1] A. Stagnaro-Green, S. H. Roman, R. H. Cobin, E. El-Harazy, A. Alvarez-Marfany, and T. F. Davies, "Detection of at-risk pregnancy by means of highly sensitive assays for thyroid autoantibodies," Journal of the American Medical Association, vol. 264, no. 11, pp. 1422-1425, 1990.

[2] K. A. Toulis, D. G. Goulis, C. A. Venetis et al., "Risk of spontaneous miscarriage in euthyroid women with thyroid autoimmunity undergoing IVF: a meta-analysis," European Journal of Endocrinology, vol. 162, no. 4, pp. 643-652, 2010.
[3] D. Glinoer, M. F. Soto, P. Bourdoux et al., "Pregnancy in patients with mild thyroid abnormalities: maternal and neonatal repercussions," Journal of Clinical Endocrinology and Metabolism, vol. 73, no. 2, pp. 421-427, 1991.

[4] B. Lejeune, J. P. Grun, P. De Nayer, G. Servais, and D. Glinoer, "Antithyroid antibodies underlying thyroid abnormalities and miscarriage or pregnancy induced hypertension," British Journal of Obstetrics and Gynaecology, vol. 100, no. 7, pp. 669$672,1993$.

[5] T. Iijima, H. Tada, Y. Hidaka, N. Mitsuda, Y. Murata, and N. Amino, "Effects of autoantibodies on the course of pregnancy and fetal growth," Obstetrics and Gynecology, vol. 90, no. 3, pp. 364-369, 1997.

[6] T. Bagis, A. Gokcel, and E. S. Saygili, "Autoimmune thyroid disease in pregnancy and the postpartum period: relationship to spontaneous abortion," Thyroid, vol. 11, no. 11, pp. 10491053, 2001.

[7] F. Ghafoor, M. Mansoor, T. Malik et al., "Role of thyroid peroxidase antibodies in the outcome of pregnancy," Journal of the College of Physicians and Surgeons Pakistan, vol. 16, no. 7, pp. 468-471, 2006.

[8] R. Negro, G. Formoso, T. Mangieri, A. Pezzarossa, D. Dazzi, and H. Hassan, "Levothyroxine treatment in euthyroid pregnant women with autoimmune thyroid disease: effects on obstetrical complications," Journal of Clinical Endocrinology and Metabolism, vol. 91, no. 7, pp. 2587-2591, 2006.

[9] D. E. Pratt, G. Kaberlein, A. Dudkiewicz, V. Karande, and N. Gleicher, "The association of antithyroid antibodies in euthyroid nonpregnant women with recurrent first trimester abortions in the next pregnancy," Fertility and Sterility, vol. 60, no. 6, pp. 1001-1005, 1993.

[10] S. Bussen and T. Steck, "Thyroid autoantibodies in euthyroid non-pregnant women with recurrent spontaneous abortions," Human Reproduction, vol. 10, no. 11, pp. 2938-2940, 1995.

[11] J. Roberts, C. Jenkins, R. Wilson et al., "Recurrent miscarriage is associated with increased numbers of CD5/20 positive lymphocytes and an increased incidence of thyroid antibodies," European Journal of Endocrinology, vol. 134, no. 1, pp. 84-86, 1996.

[12] S. S. Bussen and T. Steck, "Thyroid antibodies and their relation to antithrombin antibodies, anticardiolipin antibodies and lupus anticoagulant in women with recurrent spontaneous abortions (antithyroid, anticardiolipin and antithrombin autoantibodies and Lupus anticoagulant in habitual aborters)," European Journal of Obstetrics Gynecology and Reproductive Biology, vol. 74, no. 2, pp. 139-143, 1997.

[13] M. S. Esplin, D. W. Branch, R. Silver, and A. StagnaroGreen, "Thyroid autoantibodies are not associated with recurrent pregnancy loss," American Journal of Obstetrics and Gynecology, vol. 179, no. 6, pp. 1583-1586, 1998.

[14] W. H. Kutteh, D. L. Yetman, A. C. Carr, L. A. Beck, and R. T. Scott Jr., "Increased prevalence of antithyroid antibodies identified in women with recurrent pregnancy loss but not in women undergoing assisted reproduction," Fertility and Sterility, vol. 71, no. 5, pp. 843-848, 1999.

[15] S. Dendrinos, C. Papasteriades, K. Tarassi, G. Christodoulakos, G. Prasinos, and G. Creatsas, "Thyroid autoimmunity in patients with recurrent spontaneous miscarriages," Gynecological Endocrinology, vol. 14, no. 4, pp. 270-274, 2000.

[16] F. Mecacci, E. Parretti, R. Cioni et al., "Thyroid autoimmunity and its association with non-organ-specific antibodies and subclinical alterations of thyroid function in women with a history of pregnancy loss or preeclampsia," Journal of Reproductive Immunology, vol. 46, no. 1, pp. 39-50, 2000. 
[17] I. Marai, H. Carp, S. Shai, R. Shabo, G. Fishman, and Y. Shoenfeld, "Autoantibody panel screening in recurrent miscarriages," American Journal of Reproductive Immunology, vol. 51, no. 3, pp. 235-240, 2004.

[18] Y. Shoenfeld, H. J. A. Carp, V. Molina et al., "Autoantibodies and prediction of reproductive failure," American Journal of Reproductive Immunology, vol. 56, no. 5-6, pp. 337-344, 2006.

[19] A. T. Iravani, M. M. Saeedi, J. Pakravesh, S. Hamidi, and M. Abbasi, "Thyroid autoimmunity and recurrent spontaneous abortion in Iran: a case-control study," Endocrine Practice, vol. 14, no. 4, pp. 458-464, 2008.

[20] D. Pratt, M. Novotny, G. Kaberlein, A. Dudkiewicz, and N. Gleicher, "Antithyroid antibodies and the association with non-organ-specific antibodies in recurrent pregnancy loss," American Journal of Obstetrics and Gynecology, vol. 168, no. 3, pp. 837-841, 1993.

[21] R. G. Roussev, B. D. Kaider, D. E. Price, and C. B. Coulam, "Laboratory evaluation of women experiencing reproductive failure," American Journal of Reproductive Immunology, vol. 35, no. 4, pp. 415-420, 1996.

[22] F. H. Rushworth, M. Backos, R. Rai, I. T. Chilcott, N. Baxter, and L. Regan, "Prospective pregnancy outcome in untreated recurrent miscarriers with thyroid autoantibodies," Human Reproduction, vol. 15, no. 7, pp. 1637-1639, 2000.

[23] M. F. Reznikoff-Etievant, V. Cayol, G. M. Zou et al., "Habitual abortions in 678 healthy patients: investigation and prevention," Human Reproduction, vol. 14, no. 8, pp. 2106-2109, 1999.

[24] S. F. Abdel Aziz, A. A. Moussa, H. O. Kandil, M. Y. Shaheen, and M. M. Abou Zeid, "Antithyroid Autoantibodies in Unexplained Recurrent Abortion," 2002, http://www.obgyn.net/women/women.asp?page=/pb/cotm/ 9905/Antithyrod1.

[25] C. De Carolis, E. Greco, M. D. Guarino et al., "Antithyroid antibodies and antiphospholipid syndrome: evidence of reduced fecundity and of poor pregnancy outcome in recurrent spontaneous aborters," American Journal of Reproductive Immunology, vol. 52, no. 4, pp. 263-266, 2004.

[26] J. Bellver, S. R. Soares, C. Álvarez et al., "The role of thrombophilia and thyroid autoimmunity in unexplained infertility, implantation failure and recurrent spontaneous abortion," Human Reproduction, vol. 23, no. 2, pp. 278-284, 2008.

[27] M. F. Prummel and W. M. Wiersinga, "Thyroid autoimmunity and miscarriage," European Journal of Endocrinology, vol. 150, no. 6, pp. 751-755, 2004.

[28] L. Chen and R. Hu, "Thyroid autoimmunity and miscarriage: a meta-analysis," Clinical Endocrinology, vol. 74, no. 4, pp. 513-519, 2011.

[29] N. Benhadi, W. M. Wiersinga, J. B. Reitsma, T. G. M. Vrijkotte, and G. J. Bonsel, "Higher maternal TSH levels in pregnancy are associated with increased risk for miscarriage, fetal or neonatal death," European Journal of Endocrinology, vol. 160, no. 6, pp. 985-991, 2009.

[30] R. Negro, A. Schwartz, R. Gismondi, A. Tinelli, T. Mangieri, and A. Stagnaro-Green, "Increased pregnancy loss rate in thyroid antibody negative women with TSH levels between 2.5 and 5.0 in the first trimester of pregnancy," Journal of Clinical Endocrinology and Metabolism, vol. 95, no. 9, pp. E44-E48, 2010.

[31] A.-M. Nybo Andersen, J. Wohlfahrt, P. Christens, J. Olsen, and M. Melbye, "Maternal age and fetal loss: population based register linkage study," British Medical Journal, vol. 320, no. 7251, pp. 1708-1712, 2000.
[32] M. Imaizumi, A. Pritsker, M. Kita, L. Ahmad, P. Unger, and T. F. Davies, "Pregnancy and murine thyroiditis: thyroglobulin immunization leads to fetal loss in specific allogeneic pregnancies," Endocrinology, vol. 142, no. 2, pp. 823-829, 2001.

[33] S. T. Matalon, M. Blank, Y. Levy et al., "The pathogenic role of anti-thyroglobulin antibody on pregnancy: evidence from an active immunization model in mice," Human Reproduction, vol. 18, no. 5, pp. 1094-1099, 2003.

[34] T. Mannisto, M. Vaarasmaki, A. Pouta et al., "Perinatal outcome of children born to mothers with thyroid dysfunction or antibodies: a prospective population-based cohort study," Journal of Clinical Endocrinology and Metabolism, vol. 94, no. 3, pp. 772-779, 2009.

[35] Y. L. Lee, H. P. Ng, K. S. Lau et al., "Increased fetal abortion rate in autoimmune thyroid disease is related to circulating TPO autoantibodies in an autoimmune thyroiditis animal model," Fertility and Sterility, vol. 91, no. 5, pp. 2104-2109, 2009. 


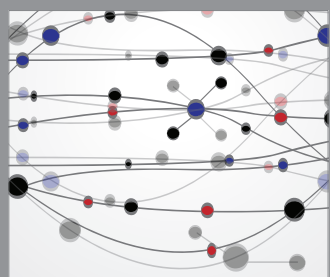

The Scientific World Journal
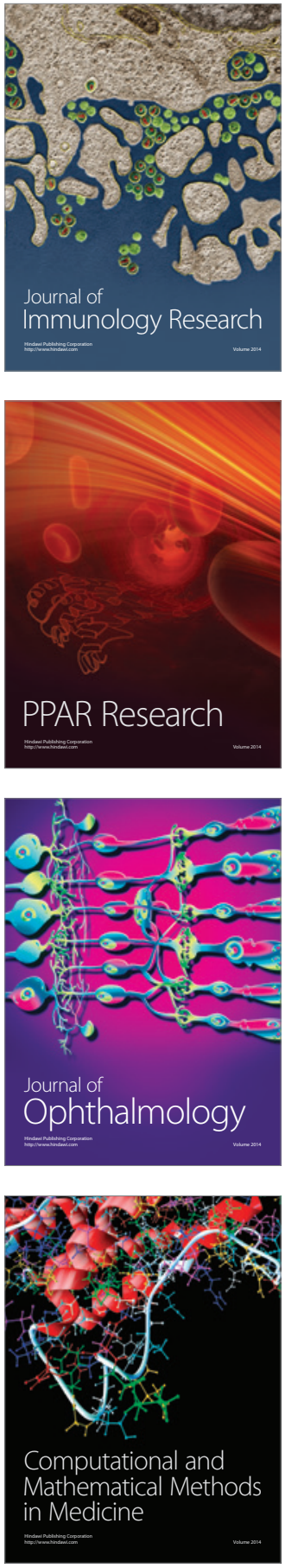

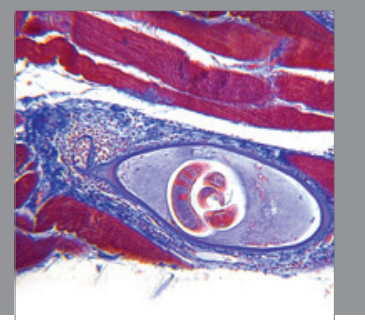

Gastroenterology

Research and Practice
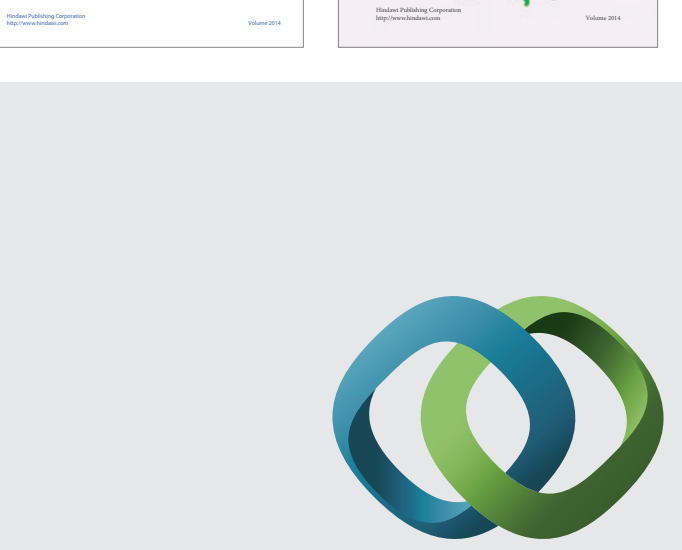

\section{Hindawi}

Submit your manuscripts at

http://www.hindawi.com
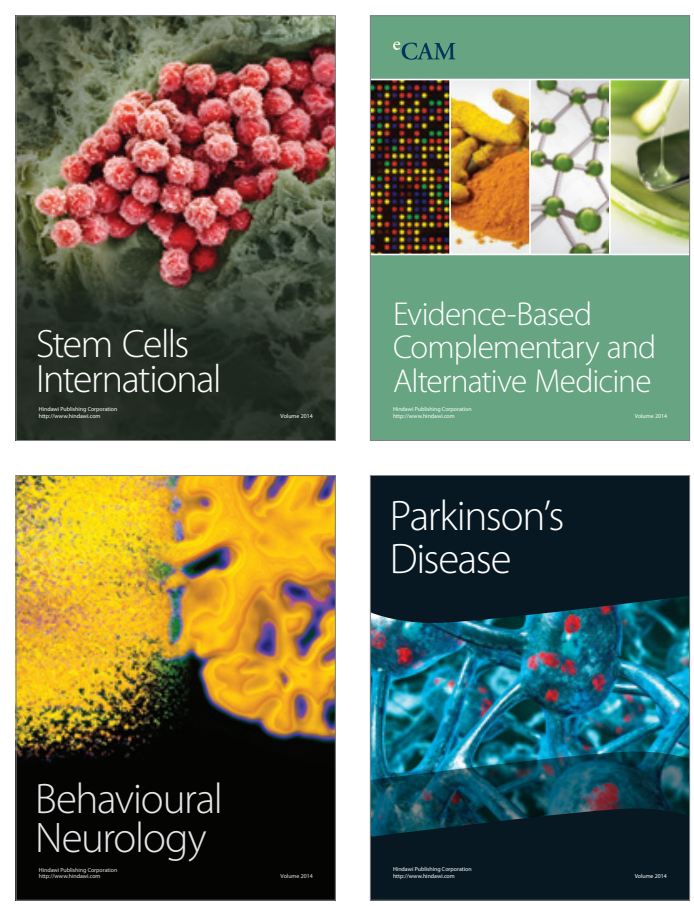

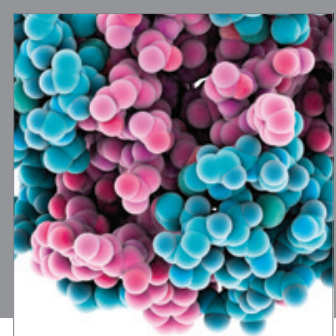

Journal of
Diabetes Research

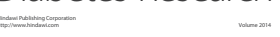

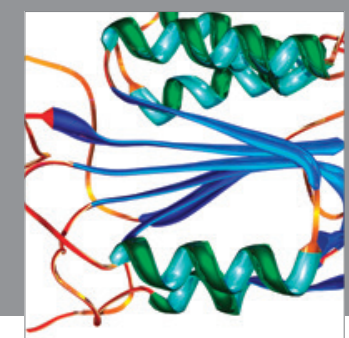

Disease Markers
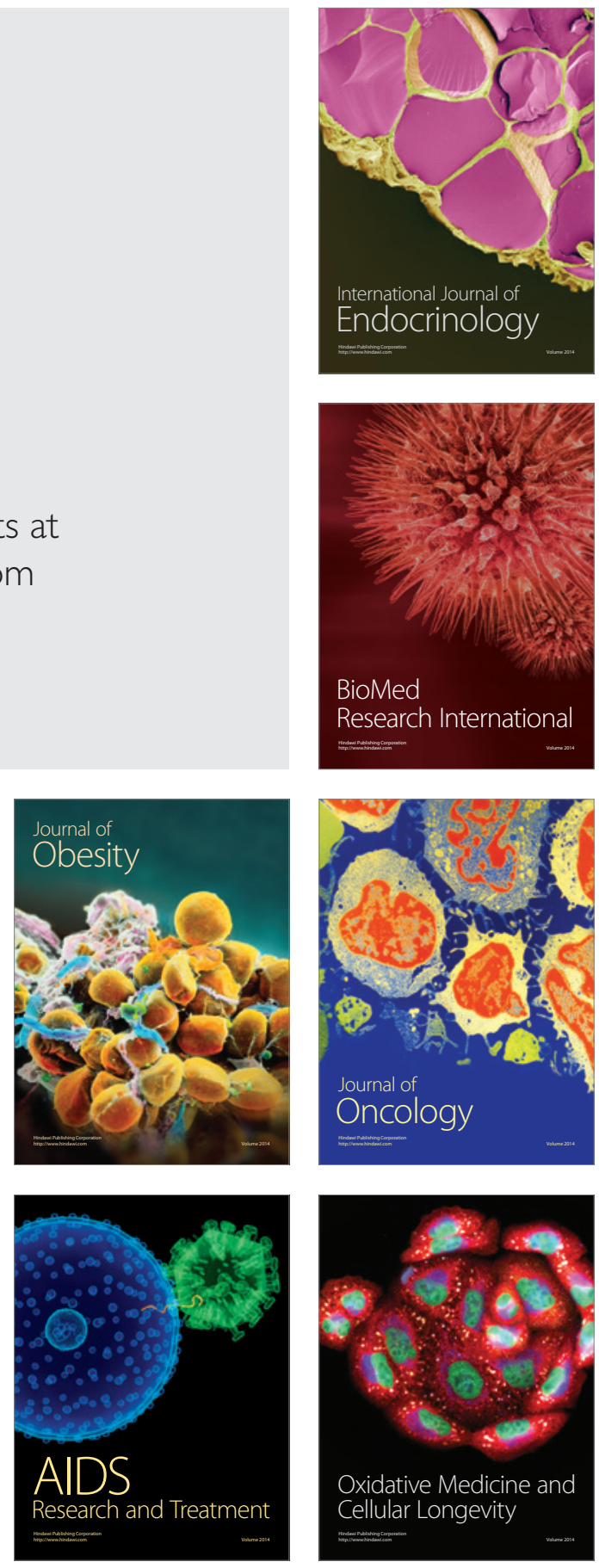